\title{
Esporotricose óssea e cutânea em canino
}

Isabel Martins MADRID ${ }^{1}$

Melissa Orzechowski

XAVIER ${ }^{1}$

Antonella Souza MATTEI ${ }^{1,2}$

Luiz Paiva CARAPETO 3

Tatiana de Ávila ANTUNES ${ }^{3}$

Ronaldo SANTOS JÚNIOR ${ }^{4}$

Márcia de Oliveira NOBRE ${ }^{3}$

Mário Carlos Araújo

MEIRELES ${ }^{1}$

\section{Correspondência para:}

Laboratório de Micologia - Departamento de Veterinária Preventiva/UFPel, campus universitário s/no ${ }^{\circ}$ cep:96010-900, Pelotas-RS, isabel_madrid@ufpel.tche.br

Recebido para publicação: 10/04/2006 Aprovado para publicação: 10/05/2007

\author{
1 - Laboratório de Doenças Infecciosas, Setor Micologia da Faculdade de Veterinária \\ da Universidade Federal de Pelotas, Pelotas-RS \\ 2 - Programa Institucional de Bolsas de Iniciação Cientifica (PIBIC), CNPq, UFPel - RS \\ 3 - Hospital de Clínicas Veterinária da Universidade Federal de Pelotas, Pelotas-RS \\ 4 - Médico Veterinário Autônomo, Consultório Veterinário PRONTOCAN, Pelotas-RS
}

\section{Resumo}

A esporotricose é uma micose subcutânea causada pelo fungo dimórfico Sporothrix schenckii. Este artigo descreve o primeiro caso de esporotricose óssea e cutânea, em canino, na cidade de Pelotas, Rio Grande do Sul. O animal apresentava lesões ulceradas e crostosas, há aproximadamente três anos no plano nasal e membro torácico direito, dispnéia e apatia. Para confirmação do diagnóstico, foram realizados exames micológico, histopatológico, radiológico e hematológico. O animal foi tratado durante três meses com $10 \mathrm{mg} / \mathrm{kg}$ de itraconazol, por via oral, obtendo-se a cura das lesões. Este estudo alerta clínicos de pequenos animais para a ocorrência desta micose em caninos na região de Pelotas, RS.

O fungo dimórfico Sporothrix schenckii, agente etiológico da esporotricose em humanos e diversas espécies animais, é transmitido, principalmente, através do implante traumático na derme, sendo considerado, atualmente, um importante patógeno de felinos domésticos. ${ }^{1,2,3} \mathrm{~A}$ esporotricose em cães apresenta-se sob a forma cutânea fixa ou disseminada, caracterizada por múltiplos nódulos subcutâneos, úlceras e crostas. Estas lesões se assemelham àquelas que ocorrem em outras dermatopatias de cães, como leishmaniose, micobacteriose, neoplasias e piodermites, sendo importante à realização de exames complementares para o correto diagnóstico. ${ }^{4}$

A esporotricose é considerada rara em cães ${ }^{5,6}$ sendo o primeiro caso de esporotricose canina descrito no Brasil, em 1964, por Londero, Castro e Fischman ${ }^{5}$, que relataram a forma cutânea disseminada. Posteriormente poucos casos de esporotricose em cães foram descritos ${ }^{7,8,9}$, mas só recentemente, Schubach et al. ${ }^{10}$ descreveram um surto com 44 casos de esporotricose cutânea canina no Rio de Janeiro, nos quais a transmissão por gatos com esporotricose ocorreu em 84,1\% dos animais, o que enfatiza o potencial do felino como transmissor desta doença. No entanto, a forma cutânea com acometimento ósseo continua sendo uma apresentação pouco encontrada.

Neste artigo descreve-se o primeiro caso de esporotricose óssea e cutânea, em canino, diagnosticado na cidade de Pelotas, Rio Grande do Sul, Brasil.

Em abril de 2005, foi atendido, em consultório veterinário, um canino, macho, sem raça definida e com nove anos de idade, que apresentava lesões cutâneas profundas caracterizadas por extensa úlcera com exsudato acastanhado e crostas, no plano nasal, e presença de vários nódulos e úlceras no membro torácico direito. A lesão no plano nasal evoluía há, aproximadamente, três anos. Durante o exame físico, observouse que o animal apresentava apatia, dispnéia, tumefação nasal e presença de secreção mucosa na cavidade nasal (Figura 1). Foram colhidas amostras de tecido e exsudato, respectivamente, com punch e zaragatoa, as quais foram encaminhadas para exame histopatológico e micológico. Como exames complementares, foram realizados hemograma e radiografia de face e tórax do animal. O processamento das amostras no 


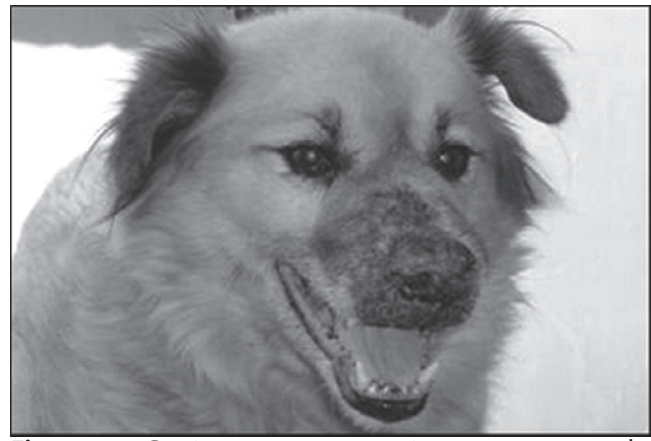

Figura 1 - Canino com esporotricose apresentando lesões cutâneas, ulceradas e crostosas, e tumefação do plano nasal

setor de micologia do Laboratório de Doenças Infecciosas foi realizado através do exame direto com esfregaço corado pelo Gram, e cultivo, em duplicata, em placas de Petri contendo ágar Sabouraud dextrose, acrescido de cloranfenicol e cicloheximida, incubadas a $25^{\circ} \mathrm{C}$ e $37^{\circ} \mathrm{C}$ por até três semanas, com observação diária. Para realização de exame histopatológico, a amostra foi encaminhada ao Laboratório Regional de Diagnóstico (LRD - UFPel) fixada em formol 10\%, sendo, posteriormente, processada e corada pela técnica de hematoxilina-eosina e Periodic Acid Schiff (PAS). Após a obtenção dos resultados laboratoriais, confirmando o diagnóstico de esporotricose, foi instituída terapia antifúngica com itraconazol na dose de $10 \mathrm{mg} / \mathrm{kg}$, por via oral, uma vez ao dia, durante três meses, com acompanhamento clínico do animal a cada 15 dias.

A localização das lesões cutâneas na cabeça e membro e as características clínicas das lesões de esporotricose observadas neste estudo são aquelas descritas na bibliografia., ${ }^{4,5,9}$

No exame direto, do tecido e exsudato, não foram visualizadas estruturas morfometricamente compatíveis com Sporothrix schenckii, sendo que, de acordo com a literatura consultada, a presença de células leveduriformes em amostras provenientes de cães e de homens é menos freqüente que em amostras de felinos, nas quais são observadas grandes quantidades de células fúngicas. ${ }^{6}$ Após 10 dias de incubação foram observadas colônias de aspecto membranoso e coloração creme- acastanhada, à $25^{\circ} \mathrm{C}$, e colônias de coloração creme e consistência cremosa à $37^{\circ} \mathrm{C}$, confirmando o dimorfismo do agente. $\mathrm{Na}$ micromorfologia das colônias, a $25^{\circ} \mathrm{C}$, verificou-se a presença de hifas hialinas, septadas e ramificadas, com conídios dispostos ao longo das hifas e ao redor do ápice do conidióforo, em forma de "margarida", e a $37^{\circ} \mathrm{C}$, células leveduriformes de formato alongado. A macro e micromorfolologia dos cultivos foram semelhantes aos descritos na literatura. ${ }^{4}$

O hemograma do canino revelou normoleucometria e anemia, determinada, provavelmente, pela cronicidade da doença e pela contínua secreção sanguinolenta das lesões. Os achados hematológicos do eritrograma deste estudo se assemelham aos descritos por Schubach et al..$^{10}$, no entanto, os achados do leucograma diferem dos descritos por estes autores, os quais observaram, principalmente, leucocitose com neutrofilia.

$\mathrm{Na}$ avaliação radiológica da face foram observados sinais de destruição óssea do tipo "roedura de traça", no osso nasal, e radiopacidade nas câmaras nasais compatíveis com osteólise (Figura 2). Na avaliação radiológica, da cavidade torácica, não foram encontradas alterações em campos pulmonares. De acordo com os achados radiológicos da face, sugere-se que o acometimento ósseo localizado na região subjacente a lesão cutânea seja decorrente da cronicidade da lesão. As alterações radiológicas

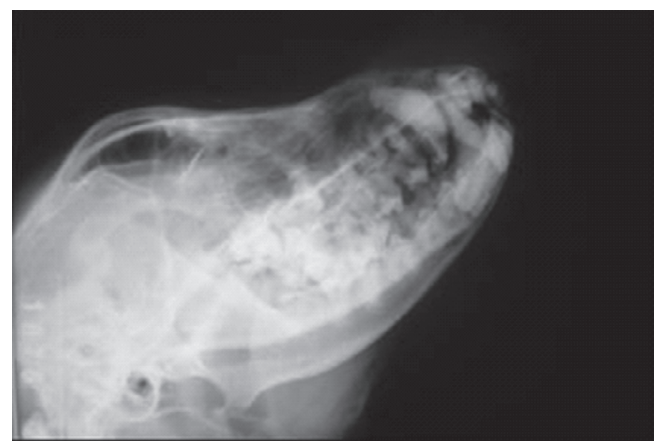

Figura 2 - Avaliação radiológica do animal com esporotricose cutânea, demonstrando sinais de destruição óssea do tipo "roedura de traça" no osso nasal, e radiopacidade nas câmaras nasais compatíveis com osteólise 
da esporotricose óssea ocorrem tardiamente e em casos de cronicidade, não apresentam características específicas ${ }^{7}$, tal como o evidenciado neste relato.

A histopatologia revelou a presença de dermatite piogranulomatosa, profunda, com infiltrado celular constituído por células mononucleares e polimorfonucleares, e presença de estruturas PAS positivas, compatíveis com Sporothrix schenckii, sendo essas alterações histopatológicas semelhantes às descritas em caninos e felinos com esporotricose. ${ }^{6}$

Aos 20 dias de tratamento da esporotricose com itraconazol foram observados sinais de progressiva remissão da doença com diminuição das úlceras e melhora da atividade respiratória. O tratamento foi realizado por três meses e o animal continua, desde a interrupção da terapia, em acompanhamento clínico para observar possível recidiva da doença. O itraconazol tem demonstrado resultados satisfatórios no tratamento desta micose intermediária, em felinos e humanos, sendo preconizado, atualmente, para o tratamento da esporotricose cutânea. ${ }^{6,9,10,11}$

Pela esporotricose canina apresentar potencial zoonótico mínimo ${ }^{6}$, é importante salientar a ocorrência desta micose em cães na localidade de Pelotas, RS, a fim de alertar clínicos de pequenos animais quanto a evolução da doença para a forma óssea e quanto a importância do exame laboratorial para a realização de diagnóstico diferencial desta micose.

\section{Cutaneos and osseous sporotrichosis in dog}

\section{Abstract}

The sporotrichosis is a subcutaneous mycosis caused by dimorphic fungus Sporothrix schenckii. This article describes the first cutaneous and osseous sporotrichosis case in canine in the Pelotas city, Rio Grande do Sul. The animal presented crusts and ulcerated lesions, approximately the three years in the nasal plan and right hind-foot, dispneic and apathy. Mycological, histopathological, radiological and hematological diagnosis was realized. The animal was treated by three months with itraconazole, administered orally at a dosage of $10 \mathrm{mg} /$ $\mathrm{kg}$, until lesions disappeared. This study alert small animals clinicians for the occurrence of this mycosis in dogs in the region of Pelotas, RS.

\section{Referências}

1 BARROS, M. B. L. et al. Sporotrichosis: an Emergent Zoonosis in Rio de Janeiro. Memórias do Instituto Oswaldo Cruz, v. 96, n. 6, p. 777-779, 2001.

2 NOBRE, M. O. et al. Recurrence of sporotrichosis in cats with zoonotic involvement. Revista Iberoamericana de Micologia, v. 18, n. 3, p. 137-140, 2001.

3 XAVIER, M. O. et al. Esporotricose felina com envolvimento humano na cidade de Pelotas, RS, Brasil. Ciência Rural, v. 34, n. 6, p. 1961-1963, 2004.

4 FARIAS, M. R. et al. Esporotricose canina e felina. Cães e Gatos, n. 66, p. 30-38, 1997.

5 LONDERO, A. T.; CASTRO, R. M.; FISCHMAN, O. Two cases of sporotrichosis in dogs in Brazil. Sabouraudia, v. 18, p. 273-274, 1964.

$6 \mathrm{SCHUBACH}$, T. M. P; SCHUBACH, A. O. Esporotricose em gatos e cães - revisão. Clínica veterinária, São Paulo, v. 5, n. 29, p. 21-24, 2000.
7 IWASAKI, M.; KAGIWARA, M. K. Skeletal Sporotrichosis in a dog. Companion Animal Pratice, v. 2, n. 4, p. 27-31, 1988.

8 LARSSON, C. E. et al. Esporotricose canina - relato de caso insólito. In: CONGRESSO BRASILEIRO DE CLÍNICOS VETERINÁRIOS DE PEQUENOS ANIMAIS, 15, 1993, Rio de Janeiro, RJ. Anais...

9 ROEDER, L. D. et al. Esporotricose canina - relato de caso. In: CONGRESSO BRASILEIRO DE ESPECIALIDADES EM MEDICINA VETERINÁRIA, 2002, Curitiba, PR. Anais... p. 175.

$10 \mathrm{SCHUBACH}, \mathrm{T}$. M. P. et al. Canine sporotrichosis in Rio de Janeiro, Brazil: clinical presentation, laboratory diagnosis and therapeutic response in 44 cases (1998-2003). Medical Micology, v. 44, p. 87-92, 2006.

11 MADRID, I. M. et al. Esporotricose felina: diagnóstico precoce $\mathrm{x}$ tratamento eficaz. In: CONGRESSO DE MICROBIOLOGIA, 2005, São Paulo, SP. Anais... 